\title{
Perinatal Outcome of Vaginal Breech Delivery versus Caesarean Breech Delivery in a Tertiary Care Center
}

\author{
Rajendra Kumar Chaudary', Rajan Ghimire², Deepak Raj Kafle ${ }^{3}$ \\ 'Department of Obstetrics and Gynecology, Pokhara Academy of Health Sciences, Kaski, Nepal, ${ }^{2}$ Department of General \\ Practice and Emergency Medicine, Tribhuvan University, Institute of Medicine, Kathmandu, Nepal, ${ }^{3}$ Department of Obstetrics \\ and Gynecology, Pokhara Academy of Health Sciences, Kaski, Nepal.
}

\section{ABSTRACT}

Introduction: Breech delivery has always been matter of interest in obstetrics. Cesarean breech delivery has been preferred method of delivery. We aim to find out any differences in outcome between vaginal breech delivery and cesarean breech delivery in our setup.

Methods: Data were collected from record book of Department of Gynaecology and obstetrics, Pokhara Academy of Health Sciences, Kaski, Nepal. Pregnant with breech presentation who had delivery in the centre from 2074 Baishak to 2074 chaitra were enrolled in the study. Data of 174 patients were analysed among which 74 underwent vaginal delivery for breech and 110 underwent cesarean breech delivery.

Results: Only 1 (1.6\%) of newborn delivered by vaginal route were admitted to NCU vs $17(15.5 \%)$ in cesarean group which was significant (odds ratio $=0.071,95 \%$ C.I 0.009-0.574; $p=0.004$ ). There was only one death of newborn which was delivered by vaginal route. Mean APGAR score at 1 and 5 minute in vaginal breech delivery was 6 and 7 and in cesarean breech delivery was 6 and 8 .

Conclusions: Though perinatal morbidity was more with cesarean breech delivery but further study with more sample size is needed before reaching conclusion.

Keywords: breech presentation; cesarean breech delivery; vaginal delivery.

\section{INTRODUCTION}

Breech presentation is a longitudinal lie of the fetus with the caudal pole (buttock or lower extremity) occupying the lower part of the uterus and cephalic pole in the uterine fundus. ${ }^{1}$ There are three types of breech presentation. In the frank breech position (48 to $73 \%$ ), both hips are flexed and both knees are extended. In the complete breech position ( 4.6 to $11.5 \%$ ), both hips and both knees are flexed. In the incomplete breech position (12.4 to 40.5), one or both hips are not completely flexed. ${ }^{2}$ Prevalence of singleton breech deliveries in the hospital was $3.4 \% .^{3}$
There is increased risk to fetus born to breech because of cord compression between cervix and body during crowning; trauma to fetus from dystocia associated to after-coming shoulders, head and arms. So breech delivery is always been as a matter of study in obstetrics.

Correspondence: Dr. Rajendra Kumar Chaudhary, Department of Obstetrics and Gynecology, Pokhara Academy of Health Sciences, Kaski, Nepal. Email: drchaudhary2990@yahoo.com, Phone: +977. 9856033415 
A study done in Lumbini medical college showed that out of 80 selected women with breech presentation, 42 of them had vaginal deliveries and 38 women had undergone caesarean section. The perinatal mortality was $4.8 \%$ and morbidity was $2 \%$ in vaginal breech deliveries. There was no significant difference of APGAR score in the two groups at any time. Similarly, there was no significant difference in perinatal morbidity and mortality in the two groups. Nulliparous women were more likely to deliver by cesarean section. ${ }^{4}$ Another study in Patan Academy of Health Sciences concluded that in well-selected cases, the neonatal outcome following assisted vaginal breech delivery and caesarean section may not be different. ${ }^{5}$

Adverse perinatal outcome in planned vaginal breech labor at term is associated with fetal growth restriction, oligohydramnios, previous cesarean delivery, gestational diabetes, nulliparity and epidural anesthesia. ${ }^{6}$ Women intending vaginal delivery had higher rates of neonatal morbidity $(6.0 \%$ vs $2.1 \%)$, neonatal birth trauma $(7.4 \%$ vs $0.9 \%)$, Apgar $<4$ at one minute $(10.5 \%$ vs $1.1 \%)$, Apgar $<7$ at five minutes (4.3\% vs $0.5 \%$ ) and neonatal intensive care unit/special care nursery admissions (16.2\% vs $6.6 \%)$ than those planning caesarean section. ${ }^{7}$ The term breech trial also concluded that perinatal mortality, neonatal mortality, or serious neonatal morbidity was significantly lower for the planned caesarean section group than for the planned vaginal birth group (17 of 1039 [1.6\%] vs 52 of 1039 [5.0\%]; relative risk 0.33 [95\% Cl 0.19-0.56]; $\mathrm{p}<0.0001)$. There were no differences between groups in terms of maternal mortality or serious maternal morbidity (41 of 1041 [3.9\%] vs 33 of 1042 [3.2\%]; $1 \cdot 24[0 \cdot 79-1 \cdot 95] ; p=0 \cdot 35) .^{8}$

As the neonatal outcome of planned cesarean breech delivery is good but in the situation like ours where pregnant lady arrives hospital in active stage of labor and vaginal trail is given. This study is aimed to find out the outcome of vaginal breech delivery in our setting.

\section{METHODS}

It is a descriptive cross-sectional study conducted among the pregnant women with breech presentation at Department of Obstetrics and Gynecology, Pokhara Academy of Health Sciences, Kaski, Nepal. Secondary data were collected from the record of the department. Pregnant with breech presentation who had delivery in the center from 2074 Baishak to 2074 Chaitra were enrolled in the study. Sample size was calculated using standard formula. ${ }^{9}$ Data of 174 patients were analyzed among which 74 underwent vaginal delivery for breech and 110 underwent cesarean breech delivery. Data on age of patients, gravida, Parity, living child, abortion, previous neonatal death, period of gestation, mode of delivery (vaginal, cesarean delivery, instrumental) outcome (APGAR score at $1 \mathrm{~min}$ and $5 \mathrm{~min}$, neonatal care unit admission, death, birth injuries) were collected. Collected data first entered into Microsoft excel first then analysed using SPSS 25.

Mean, frequencies and percentages were calculated for demographic data and categorical variables. Significance of categorical variable were analyzed using Chi square test. Multinomial logistic regression analysis was done to compare outcome among vaginal breech delivery and caesarean breech delivery.

\section{RESULTS}

From 2074 Baishak to 2074 Chaitra there were 8687 deliveries out of which $184(2.12 \%)$ were breech deliveries. Data of 184 patients were analyzed among which 74 underwent vaginal delivery for breech and 110 underwent cesarean breech delivery. Ten patients following vaginal breech delivery were excluded from studies because of missing data so 174 were included in the study. Frequencies and mean were used for categorical variables and chi-square test was used for significance test. Binary logistic regression was used for significance test of mode of delivery and its outcome. There was no significant difference between vaginal breech delivery group and cesarean breech delivery group in terms of age, parity and period of gestation.

In vaginal breech delivery group $77 \%$ were in age group 20-30 (mean $=24.2 y r s ; s . d=4.22$ ) and in cesarean delivery $67 \%$ belonged to $20-30$ yrs (mean $=24.4 \mathrm{yrs}$; $\mathrm{s} . \mathrm{d}=4.82$ ). In both groups maximum was primipara $188 \%$ in Vaginal breech delivery group and $89 \%$ in cesarean delivery group) and term delivery $181 \%$ in vaginal group and $88 \%$ in cesarean group).

Mean APGAR score at 1 and 5 minute in vaginal breech delivery was 6 and 7 and in cesarean breech delivery was 6 and 8.

Binary logistic regression was used to compare outcome among different groups. Effect of age of mother, period of gestation, parity and mode of delivery were analyzed. The results were insignificant in case of age of mother, period of gestation and parity. However, in our study only $1.6 \%$ of newborn delivered by vaginal route were admitted to NCU vs $15.5 \%$ in cesarean group which was significant (odds ratio $=0.071,95 \%$ C.I 0.009$0.574 ; \mathrm{P}=0.004$ ) (Table 2). There was only one death of newborn which was delivered by vaginal route but it was very small number so not included in analysis and need further study with large sample size. As there were no birth injuries in either of the group and none of the baby were delivered by instrumental method so 
both of these variables were not included during analysis.

\begin{tabular}{|c|c|c|c|c|c|c|c|c|c|}
\hline & \multirow[b]{3}{*}{ Count } & \multicolumn{8}{|c|}{ Mode of Delivery } \\
\hline & & \multicolumn{3}{|c|}{$\begin{array}{l}\text { Vaginal } \\
\text { delivery }\end{array}$} & \multicolumn{3}{|c|}{$\begin{array}{l}\text { Cesarean } \\
\text { delivery }\end{array}$} & \multirow[b]{2}{*}{$\mathbf{P}$} & \\
\hline & & Column \% & Row \% & $\begin{array}{c}\text { Count } \\
\%\end{array}$ & Column \% & $\begin{array}{c}\text { Row N } \\
\%\end{array}$ & $\begin{array}{c}\text { Chi } \\
\text { square }\end{array}$ & & \\
\hline \multirow{3}{*}{ Age groups } & under 20 & 11 & $17 \%$ & $34.4 \%$ & 21 & $19 \%$ & $65.6 \%$ & \multirow{3}{*}{2.5951} & \multirow{3}{*}{0.2731} \\
\hline & $20-30$ & 49 & $77 \%$ & $39.8 \%$ & 74 & $67 \%$ & $60.2 \%$ & & \\
\hline & $30-40$ & 4 & $6 \%$ & $21.1 \%$ & 15 & $14 \%$ & $78.9 \%$ & & \\
\hline \multirow{2}{*}{$\begin{array}{l}\text { Category of } \\
\text { parity }\end{array}$} & Primipara & 57 & $89 \%$ & $37.0 \%$ & 97 & $88 \%$ & $63.0 \%$ & \multirow{2}{*}{0.0308} & \multirow{2}{*}{0.8605} \\
\hline & Multipara & 7 & $11 \%$ & $35.0 \%$ & 13 & $12 \%$ & $65.0 \%$ & & \\
\hline \multirow{2}{*}{$\begin{array}{l}\text { Period of } \\
\text { gestation } \\
\text { (weeks) }\end{array}$} & $\begin{array}{l}\text { less than } 37 \\
\text { week }\end{array}$ & 12 & $19 \%$ & $48.0 \%$ & 13 & $12 \%$ & $52.0 \%$ & \multirow{2}{*}{1.5801} & \multirow{2}{*}{0.2087} \\
\hline & $>37$ weeks & 52 & $81 \%$ & $34.9 \%$ & 97 & $88 \%$ & $65.1 \%$ & & \\
\hline
\end{tabular}

Table 2. Binary logistic regression analysis of comparison of outcome among vaginal breech and cesarean breech delivery

\begin{tabular}{|c|c|c|c|c|c|c|c|c|c|c|}
\hline \multirow{4}{*}{$\begin{array}{l}\text { Age groups } \\
\text { (years) }\end{array}$} & \multirow[b]{3}{*}{ under 20} & \multicolumn{9}{|c|}{ Outcome analysis } \\
\hline & & \multicolumn{2}{|r|}{ NICU } & \multicolumn{2}{|r|}{ healthy } & \multirow[t]{2}{*}{$\begin{array}{l}\text { Chi- } \\
\text { square }\end{array}$} & \multirow[t]{2}{*}{$\mathbf{P}$} & \multicolumn{2}{|c|}{ odds ratio } & 95\% C.I \\
\hline & & 4 & $12.5 \%$ & 28 & $87.5 \%$ & & & & & \\
\hline & $20-30$ & 12 & $9.8 \%$ & 110 & $90.2 \%$ & \multirow[t]{2}{*}{0.193} & \multirow[t]{2}{*}{0.908} & \multirow[t]{2}{*}{1.059} & \multirow[t]{2}{*}{0.383} & \multirow[t]{2}{*}{2.930} \\
\hline & $30-40$ & 2 & $10.5 \%$ & 17 & $89.5 \%$ & & & & & \\
\hline \multirow{2}{*}{$\begin{array}{l}\text { Category of } \\
\text { parity }\end{array}$} & primipara & 17 & $11.1 \%$ & 136 & $88.9 \%$ & \multirow{2}{*}{0.709} & \multirow{2}{*}{0.4} & \multirow{2}{*}{3.737} & \multirow{2}{*}{0.346} & \multirow{2}{*}{40.345} \\
\hline & multipara & 1 & $5.0 \%$ & 19 & $95.0 \%$ & & & & & \\
\hline $\begin{array}{l}\text { Period of } \\
\text { gestation }\end{array}$ & $\begin{array}{l}\text { less than } 37 \\
\text { week }\end{array}$ & 4 & $16.7 \%$ & 20 & $83.3 \%$ & \multirow{2}{*}{1.172} & \multirow{2}{*}{0.279} & \multirow{2}{*}{3.356} & \multirow[b]{2}{*}{0.852} & \multirow[b]{2}{*}{13.221} \\
\hline (weeks) & $>37$ weeks & 14 & $9.4 \%$ & 135 & $90.6 \%$ & & & & & \\
\hline \multirow[t]{2}{*}{$\begin{array}{l}\text { Mode of } \\
\text { Delivery }\end{array}$} & $\begin{array}{l}\text { vaginal } \\
\text { delivery }\end{array}$ & 1 & $1.6 \%$ & 62 & $98.4 \%$ & \multirow{2}{*}{8.263} & \multirow[b]{2}{*}{.004} & \multirow[b]{2}{*}{0.071} & \multirow[b]{2}{*}{0.009} & \multirow[b]{2}{*}{0.574} \\
\hline & $\begin{array}{l}\text { cesarean } \\
\text { delivery }\end{array}$ & 17 & $15.5 \%$ & 93 & $84.5 \%$ & & & & & \\
\hline
\end{tabular}

\section{DISCUSSION}

With time and advent of safe surgical techniques more and more cesarean breech delivery are being performed worldwide. Cesarean breech delivery is considered safe mode of delivery for breech presentation.7,8,10 With more cesarean breech delivery being done, experience for vaginal breech delivery is decreasing so the risk for adverse outcome is increasing.
In the centers where vaginal breech delivery is performed more frequently outcome is still good in experienced and skilled hands. ${ }^{11-14}$ In our study there were $2.12 \%$ were breech deliveries which is similar to study conducted in Ethopia where prevalence was $3.4 \% .^{3} 15.5 \%$ newborn following cesarean breech delivery were admitted in neonatal care unit while $1.6 \%$ of newborn following vaginal breech delivery were admitted in NCU. As a subtotal population in NCU admission is less, superiority 
of vaginal delivery over cesarean delivery cannot made, further multicenter study with larger sample size is required.

\section{CONCLUSIONS}

A total of $1.6 \%$ of newborn delivered by vaginal route were admitted to NCU vs $15.5 \%$ in cesarean group which was significant lodds ratio $=0.071$, 95\% C.I 0.009-0.574; $\mathrm{P}=0.004)$. However, sample size was small so further study with larger sample size is needed.

Conflict of Interest: None.

\section{REFERENCES}

1. Alan H, Decherney M, Lauren Nathan M, Murphy Goodwin T. Current Diagnosis \& Treatment. 11th ed.; 2007. [Full Text]

2. Steven G, Jennifer Gabe R, Joe Leigh Simpson M. Obstetrics Normal and Problem Pregnancies. 5th ed.; 2007. [Full Text]

3. Mere TD, Handiso TB, Mekiso AB, Jifar MS, Ibrahim SA, Bilato DT. Prevalence and perinatal outcomes of singleton term breech delivery in Wolisso Hospital, Oromia Region, Southern Ethopia: A Cross-Sectional Study. Journal of environmental and Public Health. 2017;Article ID 9413717. [Full Text]

4. Shrestha BK, Shrestha S. Comparision of perinatal outcome of breech presentation between vaginal delivery and cesarean section. Journal of Lumbini medical college. 2016 Jan-Jun; 4(1):4-6. [Full Text]

5. Malla AP, Singh A, Shrestha R, Gurung P, Lama S, Shrestha $\mathrm{SD}$, et al. A outcome of breech delivery: caesarean section versus vaginal delivery at Patan Academy of Health Sciences, Patan. Journal of Patan Academy of Health Sciences. 2016 June; 3(1):3-9. [uued]

6. Macharey G, Gissler M, Ulander VM, Rahkoen L, Väisänen-Tommiska $M$, Nuutila $M$, et al. Risk factors associated with adverse perinatal outcome in planned vaginal breech labors at term: a retrospective population based case control study. BMC pregnancy an Childbirth. 2017;17(93). [PubMed]

7. Bin YS, Roberts CL, Ford JB, Nicholl MC. Outcomes of breech birth by mode of delivery: a population linkage study. Aust N Z J Obstet Gynaecol. 2016 oct; 56(5):453-9. [PubMed]
8. Hannah ME, Hannah WJ, Hewson SA, Hodnett ED, Saigal S, Wilan AR. Planned caesarean section versus planned vaginal birth for breech presentation at term: a randomised multicentre trial. The Lancet. 2000 October 21;356:1375-83. [PubMed]

9. Charan J, Biswas T. How to calculate Sample Size for different Study Designs in Medical Research. Indian Journal of Psychological Medicine. 2013 April; 35(2):121-6. [Full Text]

10. Berhan $Y$, Haileamlak A. The risks of planned vaginal breech delivery versus planned caesarean section for term breech birth: a meta-analysis including observational studies. BJOG. 2016 Jan;123(1):49-57. [PubMed]

11. ACOG committee on obstertic practice. Mode of Term Singleton Breech. In Committee Opinion. 2006. [Full Text]

12. Dohbit JS, Fourmane P, Tochie JN, Momoudou F, Tankeu R, Aletum $\mathrm{V}$, et al. Maternal and neonatal outcomes of vaginal breech delivery for singleton term pregnancies in a carefully selected Cameroonian population: a cohort study. British Medical Journal open. 2017 Nov 22;7(11):e017198. [Full Text]

13. Kostaska A, Menticoglou S, Gagnon R. Vaginal Delivery of Breech Presentation. Journal of Obstetrics and Gynaecology Canada. 2009 June;31(6):557-66. [uㅏ.

14. Fonseca A, Silva R, Rato I, Neves AR, Peixoto C, Ferraz Z, et al. Breech Presentation: Vaginal Versus Cesarean Delivery, which intervention leads to best outcomes? Acta Med Port. 2017 Jun;30(6):479-84. [PubMed]

15. Bin YS, Roberts CL, Ford JB, Nicholl MC. Outcomes of breech birth by mode of delivery: a population linkage study. Australian and New Zealand Journal of Obstetrics and Gynaecology. 2016;56:453-9. [PubMed]

The Author(s) 2018.

This work is licensed under a Creative Commons Attribution 4.0 International License. The images or other third party material in this article are included in the article's Creative Commons license, unless indicated otherwise in the credit line; if the material is not included under the Creative Commons license, users will need to obtain permission from the license holder to reproduce the material. To view a copy of this license, visit http://creativecommons.org/licenses/by/4.0/ 